\title{
Adefovir for lamivudine resistant HBV: More than meets the eye
}

\section{To the Editor:}

We read with interest the paper by Buti et al. [1] reporting the virological events recorded retrospectively in a cohort of 54 patients with lamivudine (LAM)-resistant chronic hepatitis B under prolonged treatment with adefovir (ADV). After emergence of LAM resistance, about half of the patients were switched to ADV monotherapy while the others received ADV as an add-on combination. Buti et al.'s report is the first long-term observation in non-Oriental patients with high viral load (mean HBV-DNA $6.9 \mathrm{log}$ ) and high rate of $\mathrm{HBeAg}$ positivity ( $46 \%$ of cases). The Authors considered three events as endpoints: (a) virological response defined by HBV-DNA $<10^{4}$ copies $/ \mathrm{ml}$ within the first 12 months of treatment, (b) $\mathrm{HBeAg}$ loss, and (c) emergence of mutations conferring ADV resistance. Since this is an important report likely to influence practice, some limits of the study are worth noting.

HBV-DNA was quantified using a real-time PCR assay with a detection limit of $10^{3}$ copies $/ \mathrm{ml}$, but virological response to antiviral therapy was instead defined by HBV-DNA levels less than $10^{4}$ copies $/ \mathrm{ml}$. Baseline HBV-DNA levels are not reported separately for $\mathrm{HBeAg}$ positive and negative patients, and for patients who received monotherapy or combination. A complete and sustained virological response, defined by undetectable HBV-DNA $\left(<10^{3}\right.$ copies $\left./ \mathrm{ml}\right)$, was observed in 16 (55.1\%) HBeAg negative but only in $5(20 \%) \mathrm{HBeAg}$ positive patients. Only those $\mathrm{HBeAg}$ positive patients with undetectable HBV-DNA levels at month 12 of treatment eventually achieved $\mathrm{HBeAg}$ loss.

In the group taken as a whole, the parameters predicting independently virological response were gender, $\mathrm{HBeAg}$ negativity and low HBV-DNA levels, but not HBV genotype. In recent years two separate studies $[2,3]$ have already reported that $\mathrm{HBeAg}$ negative patients with low pre-treatment HBV-DNA experience on ADV an earlier and more significant decline of HBV-DNA to undetectable levels. Buti and co-workers conclude that genotype D and lower baseline HBVDNA levels independently predict the likelihood of $\mathrm{HBeAg}$ loss in $\mathrm{HBeAg}$ positive, but at univariate analy- sis pre-treatment HBV-DNA and HBV genotype were not significant and only HBV genotype $\mathrm{D}$ predicted the loss of $\mathrm{HBeAg}$ at multivariate analysis. Hence in the analysis of factors predicting virological response it would be more appropriate to deal separately with $\mathrm{HBeAg}$ positive and $\mathrm{HBeAg}$ negative patients, since the endpoints of antiviral treatment are somewhat different.

Buti and co-workers also report that HBV mutations conferring resistance to ADV developed in 8 patients $(14.8 \%)$, and estimate a yearly incidence rate of $7.4 \%$. All patients with ADV-resistant mutations were nonresponders (HBV-DNA $>10^{4}$ copies $/ \mathrm{ml}$ ) or suboptimal responders (HBV-DNA between $10^{3}$ and $10^{4}$ copies $/ \mathrm{ml}$ ) after 12 months of treatment. These mutations emerged more often in the 28 patients treated with monotherapy $(17.8 \%)$, at a rate similar to that reported in other studies $[3,4]$, than in the 26 patients receiving add-on combination therapy $(11.4 \%)$. This rate is distinctly higher than that expected according to what has been reported by others who used ADV as an add-on to LAM. In fact, no ADV-resistant mutants were detected in 74 patients by Lampertico et al. [2] over 24 months of follow up and in 28 patients followed over 36 months by Rapti [3]. Furthermore, a large multicenter cohort study of $588 \mathrm{HBeAg}$ negative patients recently performed in Italy [5] found that mutations conferring resistance to ADV occurred far more commonly in patients receiving ADV monotherapy than in those on LAM-ADV combination ( $5 \%$ vs. $0.8 \%, p<0.01)$. Data from the latter study show convincingly that, in LAMresistant patients, the combination of ADV and LAM reduces the risk of virological breakthrough and of genotypic resistance to $\mathrm{ADV}$ in comparison to $\mathrm{ADV}$ monotherapy, although it does not suppress HBV replication more rapidly.

Finally, the study by Buti and co-workers contains a fairly high proportion $(37 \%)$ of patients with cirrhosis. In them the rate of ADV resistance was high: $25 \%$. The Authors do not report how many patients with cirrhosis were treated with monotherapy or combination, but state that all patients developing ADV resistance were 
non-responders or suboptimal responders. In our experience (Di Marco and Craxi, unpublished data) in 20 LAM-resistant cirrhotic patients who have been on LAM plus add-on ADV for a mean of $31 \pm 17.2$ months, only one $(5 \%)$ has developed an ADV resistance mutation at site N236T, without ALT breakthrough. The difference in the rate of ADV resistance might be related to the depth of viral suppression obtained in our patients, who had in all cases a decline of HBV-DNA to undetectable levels $(<200 \mathrm{IU} / \mathrm{ml})$, while in Buti's cohort more than $50 \%$ of patients seemingly did not achieve complete viral suppression.

It is thus fair to conclude that:

- In patients with LAM resistance and high levels of $\mathrm{HBV}-\mathrm{DNA}$, especially if $\mathrm{HBeAg}$ positive, it may be difficult to obtain a strong virological suppression with ADV.

- Restrictive criteria are needed to define virological response (HBV-DNA $<10^{3}$ copies/ml or $200 \mathrm{IU} / \mathrm{ml}$ ).

- Early finding of non-response or of suboptimal response after 9-12 months of ADV therapy suggests a high risk of emergence of ADV-resistant strains and should prompt a change of treatment strategy. In patients with cirrhosis, due to the risk of liver failure, treatment changes should be considered even earlier, at 3-6 months.

\section{References}

[1] Buti M, Elefsiniotis I, Jardi R, Vargas V, Rodriguez-Frias F, Schapper M, et al. Viral genotype and baseline load predict the response to adefovir treatment in lamivudine-resistant chronic hepatitis B patients. J Hepatol 2007;47:366-372.

[2] Lampertico P, Viganò M, Manenti E, Iavarone M, Lunghi G, Colombo M. Adefovir rapidly suppresses hepatitis B in $\mathrm{HBeAg}$ negative patients developing genotypic resistance to lamivudine. Hepatology 2005;42:1414-1419.

[3] Rapti I, Dimou E, Mitsoula P, Hadziyannis SJ. Adding-on versus switching-to adefovir therapy in lamivudine-resistant $\mathrm{HBeAg}$ negative chronic hepatitis B. Hepatology 2007;45:307-313.

[4] Yeon JE, Yoo W, Hong SP, Chang YJ, Yu SK, Kim JH, et al. Resistance to adefovir dipivoxil in lamivudine resistant chronic hepatitis B patients treated with adefovir dipivoxil. Gut 2006;55:1488-1495.

[5] Lampertico P, Marzano A, Levrero M, Santantonio T, Di Marco $\mathrm{V}$, Brunetto $\mathrm{M}$, et al. on behalf of the AISF Adefovir Study Group. Adefovir and lamivudine combination therapy is superior to adefovir monotherapy for lamivudine-resistant patients with HBeAg-negative chronic hepatitis B. J Hepatol 2007;46:S191.

Vito Di Marco

Antonio Craxì

GI \& Liver Unit, DI.BI:M.I.S., Policlinico, University of Palermo,

Palermo, Italy

E-mail address: craxanto@unipa.it (A. Craxì).

doi:10.1016/j.jhep.2007.07.013

\section{Adefovir for lamivudine resistant HBV: More than meets the eye - Reply}

\section{To the Editor:}

We read with great interest the letter by Di Marco et al., where they report their experience with the use of adefovir for lamivudine resistant patients with chronic hepatitis B. Their suggestions describe the current limitations in adefovir salvage treatment in patients with lamivudine resistance.

The authors of the letter claim that it may be difficult to obtain strong virological suppression with adefovir in patients with lamivudine resistance and high HBV DNA levels, especially in $\mathrm{HBeAg}$ positive patients, and that early findings of suboptimal response after 9-12 months of adefovir therapy suggest a high risk for the emergence of adefovir resistant strains [1].

We fully agree with these comments and the need to achieve strong suppression in viral replication defined by undetectable levels of HBV DNA using sensitive PCR assays.

Regarding baseline HBV DNA levels, in our study, HBeAg-positive patients had significantly higher HBV-DNA levels (log $7.4 \pm 1.15)$ than HBeAg-negative patients $(\log 6.62 \pm 1.29)(p=0.02)$ and exhibited significantly lower virological response rates (48\% vs $89.3 \%$ ). We did not perform a multivariate analysis for factors predicting virological response separating $\mathrm{HBeAg}$ positive ( 25 cases) vs $\mathrm{HBeAg}$ negative (29 cases) due to the small number of cases and the consequent lack of power to detect associations. In addition, HBV genotype was not a statistically significant parameter for predicting virological response in the whole dataset (log-rank test, $p$-value $=0.11$; univariate $\mathrm{Cox} \mathrm{PH}$ model, $p$-value $=$ $0.20)$. Consequently, the likelihood of detecting statistical significance in a very small dataset is very low.

The higher rates of adefovir related mutations observed in our study compared to other European studies, which included only $\mathrm{HBeAg-negative} \mathrm{patients} \mathrm{[3,4],}$ are probably related to the high proportion of $\mathrm{HBeAg}$ positive patients $(46 \%)$ with high HBV DNA levels at the time of starting adefovir rescue therapy. These differences and the observations by Lampertico et al. showing that early add-on treatment with adefovir after the emergence of lamivudine resistance before HBV DNA levels 